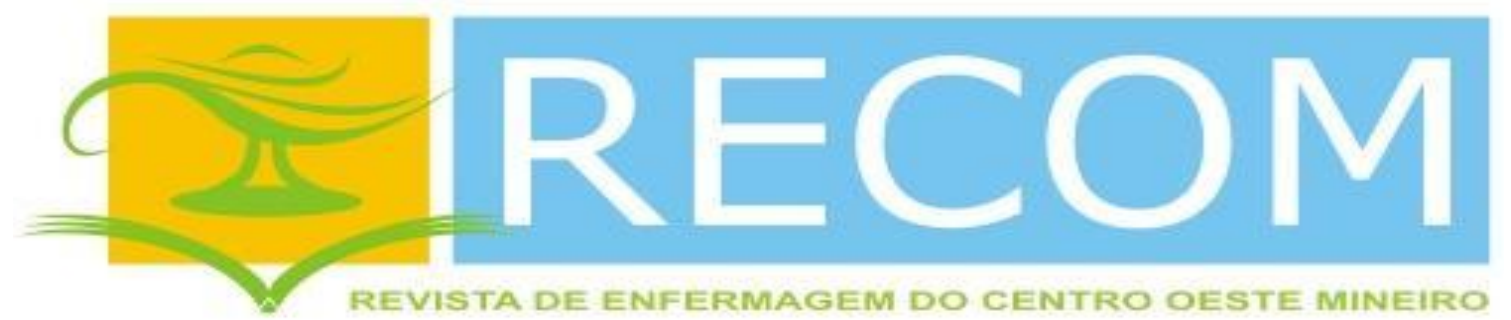

\title{
EDITORIAL
}

Christiane Inocêncio Vasques

Professora Adjunta do Departamento de Enfermagem da Faculdade de Ciências da Saúde da Universidade de Brasília (UnB)

\section{A importância da pesquisa clínica para o avanço da enfermagem}

Em um mundo em constante desenvolvimento como o nosso, novos medicamentos, tecnologias e produtos são lançados no mercado diariamente, o que pode representar inúmeras aquisições ao processo de cuidar de enfermagem. No entanto, a incorporação de novos conhecimentos na prática clínica não acontece na mesma velocidade, pois é necessário avaliar se esses trarão benefícios reais para a assistência de enfermagem ${ }^{(1)}$.

A prática baseada em evidências auxilia no processo de incorporação desses novos conhecimentos na prática clínica por meio das revisões sistemáticas, que buscam identificar a melhor evidência científica disponível. 0 que ocorre é que nem sempre existem evidências científicas fortes o suficiente que possam subsidiar a tomada de decisão de enfermeiros acerca de uma determinada situação. Nesse caso, se faz necessário o desenvolvimento de estudos clínicos que avaliem a efetividade, segurança e custo-benefício de intervenções atuais.

Os termos pesquisa clínica, estudo clínico ou ensaio clínico são utilizados para representar uma investigação científica que envolve seres humanos, cujos resultados podem gerar novos conhecimentos sobre procedimentos, medicamentos ou intervenções que melhorem a saúde das pessoas ${ }^{(2)}$. Todavia, a pesquisa clínica apresenta histórico recente pautado, principalmente, nos avanços dos conceitos de boas práticas clínicas, consolidado em 1988 e na aprovação da Resolução CNS 196/96, que regula as pesquisas com seres humanos em nosso país $^{(3)}$.

Observa-se que os estudos clínicos desenvolvidos no Brasil ainda são conduzidos, em sua maioria, por docentes e alunos dos cursos de pós-graduação ${ }^{(4)}$. Ressalta-se que são estudos que demandam tempo e investimento financeiro alto, o que pode refletir na realização de poucos estudos deste tipo por parte de profissionais que estão vinculados estritamente à assistência. Entretanto, esses enfermeiros devem ser estimulados a propor estudos clínicos, pois estão em contato direto com novas intervenções e necessidades de cuidado requeridas por pacientes sob 
sua assistência, o que faz com que eles possam, com a pesquisa, responder questões extremamente pertinentes a prática clinica e estabelecer condutas que melhorem a qualidade da assistência de enfermagem.

Para que a enfermagem avance enquanto ciência e para que avance a qualidade do cuidado prestado, é preciso produzir conhecimentos que fundamentem as intervenções de enfermagem no processo de cuidar. Para isso, é necessária a condução de estudos clínicos que testem e avaliem intervenções de enfermagem, sejam elas novas ou aquelas utilizadas empiricamente há anos; a fim de que, baseado nos resultados obtidos, a prática clínica seja modificada.

\section{Referências}

1. Pedrolo E, Danski MTR, Mingorance P, Lazzari LSM, Méier MJ, Crozeta K. A prática baseada em evidências como ferramenta para prática profissional do enfermeiro. Cogitare enferm. 2009;14(4):760-3.

Disponível

em:

http://ojs.c3sl.ufpr.br/ojs/index.php/cogitare/article/view/16396.

2- Aguiar DF, Camacho KG. O cotidiano do enfermeiro em pesquisa clínica: um relato de experiência. Rev Esc Enferm USP. 2010;44(2):526-30. Disponível em: http://www.scielo.br/pdf/reeusp/v44n2/40.pdf.

3- Laranjeira LN, Marcílio CS, Guimarães HP, Avezum A. Boas práticas clínicas: padrão de pesquisa clínica. Rev Bras Hipertens. 2007;14(2):121-123. Disponível em: http://departamentos.cardiol.br/dha/revista/14-2/14-praticas.pdf.

4- Pedrolo E, Schneider F, Pott FS, Rinaldi EC, Meier MJ, Danski MTR. Pesquisa clínica em enfermagem: contribuições para inovação tecnológica. Rev. Min. Enferm. 2012;6(3):445-453. Disponível em: http://www.reme.org.br/artigo/detalhes/548 